\title{
Cntn4, a risk gene for neuropsychiatric disorders, modulates hippocampal synaptic plasticity and behavior
}

Asami Oguro-Ando ${ }^{1,2}$, Rosemary A. Bamford ${ }^{1}$, Wiedjai Sital' ${ }^{2}$, Jan J. Sprengers $\mathbb{E}^{2}$, Amila Zuko ${ }^{2,3}$, Jolien M. Matser $\mathbb{E}^{2}$, Hugo Oppelaar ${ }^{2}$, Angela Sarabdjitsingh ${ }^{2}$, Marian Joëls ${ }^{4}$, J. Peter. H. Burbach ${ }^{2}$ and Martien J. Kas $\mathbb{B}^{2,5}$

\begin{abstract}
Neurodevelopmental and neuropsychiatric disorders, such as autism spectrum disorders (ASD), anorexia nervosa (AN), Alzheimer's disease (AD), and schizophrenia (SZ), are heterogeneous brain disorders with unknown etiology. Genome wide studies have revealed a wide variety of risk genes for these disorders, indicating a biological link between genetic signaling pathways and brain pathology. A unique risk gene is Contactin 4 (Cntn4), an Ig cell adhesion molecule (IgCAM) gene, which has been associated with several neuropsychiatric disorders including ASD, AN, AD, and SZ. Here, we investigated the Cntn4 gene knockout (KO) mouse model to determine whether memory dysfunction and altered brain plasticity, common neuropsychiatric symptoms, are affected by Cntn4 genetic disruption. For that purpose, we tested if Cntn4 genetic disruption affects CA1 synaptic transmission and the ability to induce LTP in hippocampal slices. Stimulation in CA1 striatum radiatum significantly decreased synaptic potentiation in slices of Cntn4 KO mice. Neuroanatomical analyses showed abnormal dendritic arborization and spines of hippocampal CA1 neurons. Shortand long-term recognition memory, spatial memory, and fear conditioning responses were also assessed. These behavioral studies showed increased contextual fear conditioning in heterozygous and homozygous KO mice, quantified by a gene-dose dependent increase in freezing response. In comparison to wild-type mice, Cntn4-deficient animals froze significantly longer and groomed more, indicative of increased stress responsiveness under these test conditions. Our electrophysiological, neuro-anatomical, and behavioral results in Cntn4 KO mice suggest that Cntn4 has important functions related to fear memory possibly in association with the neuronal morphological and synaptic plasticity changes in hippocampus CA1 neurons.
\end{abstract}

\section{Introduction}

Neurodevelopmental and neuropsychiatric disorders are a group of heterogeneous brain disorders with unknown etiology. More than 300 million people (4.4\%) of the world population suffer from a common mental disorder that involves a suicide attempt, significant work disability, or repeated serious violent behavior ${ }^{1}$. A large number of genome-wide studies have shown that genetic

\footnotetext{
Correspondence: Martien J. Kas (m.j.h.kas@rug.nl)

'University of Exeter Medical School, University of Exeter, Exeter EX2 5DW, UK ${ }^{2}$ Department of Translational Neuroscience, Brain Center Rudolf Magnus, UMC Utrecht, Stratenum 4.205, P.O. Box 85060, 3508 AB Utrecht, The Netherlands Full list of author information is available at the end of the article
}

variations, including deletions or duplications, contribute to these disorders by causing imbalances in gene dosage ${ }^{2}$. Interestingly, recent genetic studies have shown several genes that are common in different neuropsychiatric disorders, suggesting that there may be some common phenotype underlying disorders of different psychiatric classifications $^{3}$. To understand the mechanism of how these shared genes are involved in neuropsychiatric disorders may provide insights into how these neurodevelopmental disorders progress.

Genetic variations in neural cell adhesion molecules have been observed across neuropsychiatric disorders. These molecules have important functions for neuronal

\section{(c) The Author(s) 2021}

\footnotetext{
(c) Open Access This article is licensed under a Creative Commons Attribution 4.0 International License, which permits use, sharing, adaptation, distribution and reproduction cc) in any medium or format, as long as you give appropriate credit to the original author(s) and the source, provide a link to the Creative Commons license, and indicate if changes were made. The images or other third party material in this article are included in the article's Creative Commons license, unless indicated otherwise in a credit line to the material. If material is not included in the article's Creative Commons license and your intended use is not permitted by statutory regulation or exceeds the permitted use, you will need to obtain permission directly from the copyright holder. To view a copy of this license, visit http://creativecommons.org/licenses/by/4.0/.
} 
interactions and supporting neuronal developmental processes including neurite outgrowth and axon guidance $^{4,5}$. Contactin $4(\mathrm{Cntn} 4)$ is one of the proteins belonging to the contactins, a specific subclass of the immunoglobulin CAM superfamily $(\operatorname{IgCAM})^{6}$. These proteins share $40-60 \%$ homology at the amino acid sequence level ${ }^{7}$. Contactins are associated with neurodevelopmental processes, for example, Cntn1 plays an important role in oligodendrocyte maturation and myelination ${ }^{8}$ and Cntn6 plays a role in dendritic arborization of deep layer cortical neurons and axon branching in the corticospinal tract ${ }^{9}$. Considering the central role of contactins in neurodevelopment this constitutes a potentially interesting group of proteins to investigate in closer depth their functional relation with neuropsychiatric pathology development. This proposal is supported by a previous study identifying certain regions with rare $\mathrm{CNVs}$ that were observed in several anorexia nervosa (AN) patients, including CNVs disrupting the Cntn6/Cntn4 region $^{10}$. Cntn4 and Cntn6 have also been reported as candidate risk genes or with associated mutations in Alzheimer's disease $(\mathrm{AD})^{11-13}$ and schizophrenia $(\mathrm{SZ})^{14}$ with at least one significant SNP found in Cntn $4^{15}$.

To understand the neuronal function of Cntn4, we require knowledge of expression and localization of Cntn4 in the nervous system. Expression of contactins is observed in the peripheral as well as the central nervous system in rodents ${ }^{16}$, whereas Cntn4 is expressed in the olfactory bulb, thalamus, hippocampus, and cerebral cortex; sites suggested to play a role in neuropsychiatric phenotypes ${ }^{17-20}$. Cntn4 has extensive expression in the cortex, namely in layers $\mathrm{II}^{-} \mathrm{V}^{17}$. Recent single-cell RNA sequencing shows that Cntn4 is expressed in pyramidal neurons and in VIP- and SST-expressing interneurons of the cortex and in CA granule cells and interneurons of the hippocampus ${ }^{21}$. CNTN4 is detectable during embryonic development and into adulthood within the axons of olfactory sensory neurons. Functionally, CNTN4 can act as an axon guidance molecule crucial to the proper formation and development of the olfactory and optic systems ${ }^{22-24}$. These expression patterns suggest that Cntn4 might play a role in the formation of axon connections and support of neural circuits in these regions during the development of the nervous system. Cntn4 in mice resembles its human orthologue $\mathrm{e}^{25}$, therefore investigating the anatomical phenotype in knockout mouse models should reveal the role of Cntn4 in normal and abnormal development.

We present here functional investigations using a Cntn4 gene knockout mouse model to understand how Cntn4 loss-of-function impacts brain development and behavior. This study focuses on the hippocampus since Cntn4 is highly expressed in this brain region and because of its involvement in learning and memory performance, a phenotype commonly affected in a wide variety of psychiatric disorders ${ }^{26-28}$. In addition, we begin our understanding of Cntn4 function in the hippocampus because several IgCAMs have shown to be involved in the development of the dentate gyrus (DG) of the hippocampus. IgCAM deletions have been shown to affect mossy fiber tracts in the hippocampus likely due to fasciculation defects $^{29-32}$, especially since expression is localized specifically in the dentate gyrus granule cells ${ }^{23}$. In addition, previous studies revealed phenotypic differences in the cerebral cortex and hippocampus of $\mathrm{Cntn} 6^{-1-}$ mice $^{33}$. CNTN6 and CNTN4 are neighboring genes and share over $70 \%$ of amino acid identity ${ }^{34}$, all indicating that CNTN proteins may share important functions for neuronal development. In this study, the role of Cntn4 in hippocampal functioning was assessed at the neuro-anatomical, electrophysiological, and behavioral level. Understanding the neurobiological mechanisms underlying brain abnormalities in the hippocampus may eventually contribute to developing clinical treatments with a transdiagnostic application.

\section{Materials and methods}

Full details of materials and methods are provided in the Supplementary Information.

\section{Animals}

Cntn4-deficient mice were kindly provided by Dr. Yoshihiro Yoshihara (RIKEN, Japan). These mice were generated using a standard gene-targeting method as previously described ${ }^{23}$. Mice were genotyped at six weeks of age by PCR with extracted DNA and specific primers for Cntn4 (Table S1). All mice were kept on a normal day/ night cycle and had access to food and water ad libitum (UMC, Utrecht). All experimental procedures are performed according to the institutional guidelines of the University Medical Center (UMC) Utrecht. All animal procedures were performed according to $\mathrm{NIH}$ guidelines and approved by the European Council Directive (86/609/ $E E C)$. The rationale of using a male only sample is based on the male predominance of ASD and the potential sex differences.

\section{Electrophysiology}

Healthy 8-12 week old male mice were used for electrophysiology experiments as described previously ${ }^{35}$. One brain slice at a time was moved to a recording chamber with constant perfusion of aCSF $\left(32{ }^{\circ} \mathrm{C}\right.$, flow rate $1.2-1.5 \mathrm{~mL} /$ min). Field Excitatory Postsynaptic Potentials (fEPSPs) were recorded in the Schaffer collateral-CA1 pathway as described previously $^{36,37}$. In a separate series of slices a single $100 \mathrm{~Hz}$, $1 \mathrm{~s}$ stimulation was applied. Data is pooled for baseline presynaptic characteristics $10 \mathrm{~Hz}$ and $100 \mathrm{~Hz}$ since the data is collected before HFS was applied. Data were acquired, stored, 
and analyzed using Signal 2.16 (Cambridge 159 Electronic Design, United Kingdom).

\section{Nissl staining and immunohistochemistry}

Nissl staining and immunohistochemistry was carried out as described previously ${ }^{32}$.

\section{Golgi staining}

Golgi staining was performed using a FD Rapid GolgiStain $^{\mathrm{TM}}$ kit (FD NeuroTechnologies, Columbia, MD, USA) according to the instructions of the manufacturer.

\section{Corticosterone assay}

Corticosterone levels were determined as previously described $^{38}$.

\section{Behavior}

For behavioral studies, $\mathrm{Cntn} 4$ gene knockout mice were maintained on a C57BL/6 J (Black 6J) genetic background. Littermate wild type, heterozygous and homozygous Cntn4 gene knockout animals for behavioral testing were obtained through heterozygous crossings. Measurements were performed during the dark phase of the day, which is the habitual active phase of this nocturnal species, as described previously ${ }^{39}$. A total of 38 male mice, consisting of $12 \mathrm{Cntn}^{+/+}, 13 \mathrm{Cntn}^{+/-}$, and 13 $\mathrm{Cntn}^{-1-}$ mice, were divided into three testing batches of 12 or 13 mice that were randomized for genotype. Behavior tests were carried out as described previously ${ }^{40}$.

\section{Experimental design and statistical analysis}

All experiments were designed to include sample numbers for accurate and appropriate statistical tests, and in accordance to ethical guidelines.

To ensure the experiments had appropriate statistical Power, a Dunn-Sidak correction for the alpha was carried out as follows: $1-[1-0.05]^{\wedge} 1 / C$, with $C$ the number of comparisons multiplied by the number of parameters. Power analysis is based on the main parameters of error trials during reversal; differences between the means $=3$, $\mathrm{SD}=2$. The number of main parameters (no. of errors, no. of trials to criterion) that need to be corrected for is 2 .

All data were analyzed using GraphPad Prism 5 (GraphPad Software, Inc.) For statistical analysis, data is plotted as the mean \pm standard error of the mean, unless otherwise stated. Statistical tests were chosen based on data being quantitative and the number of samples. All data was checked prior to statistical tests being carried out that assumptions of the tests were met. Variation within groups of data is estimated by ANOVA output and is checked to be similar between groups of data that are being statistically compared. For all tests, a $P$ value $<0.05$ was considered significant. Heterozygous mice were included where differences between homozygous and wild-type mice were observed. The investigators were blinded to the genotype during experiments and during assessing the out-coming results.

Electrophysiology: paired pulse ratio and baseline synaptic characteristics were analyzed by two-way ANOVA. Synaptic potentiation was analyzed using the unpaired Student's $t$ test and one-way ANOVA. $10 \mathrm{~Hz} C n t n 4^{+/+}: n=8$, Cntn $^{+/-}: n=6$, Cntn $^{-1-}: n=5$ mice. $100 \mathrm{~Hz} \mathrm{Cntn} 4^{+/+}$: $n=7$, Cntn $^{+--}: n=9$, Cntn $^{-1-}: n=7$ mice.

Nissl staining: statistical analysis between genotypes was performed using unpaired Student's $t$ test and one-way ANOVA. Analysis was performed on at least two sections per brain from $\mathrm{Cntn} 4^{+/+}, \mathrm{Cntn} 4^{+/-}$, and $\mathrm{Cntn} 4^{-/-}$mice ( $n=4$ mice per genotype).

Immunohistochemistry: statistical analysis was performed between genotypes on cell/neuron number and mossy fiber data using unpaired Student's $t$ test and oneway ANOVA. Analysis was performed on at least three sections per brain from $\mathrm{Cn} n n 4^{+/+}$and $\mathrm{Cntn} 4^{-/-}$mice $(n=$ 6 mice per genotype).

Golgi staining: quantitative analysis between genotypes was performed, in each CA1 area, on at least six slices in $\mathrm{Cntn}^{+/+}, \mathrm{Cntn} 4^{+/-}$, and Cntn $4^{-/-}$mice ( $n=5$ mice per genotype) using the unpaired Student's $t$ test. Neuron data $n=19\left(\mathrm{Cntn}^{+/+}\right), \quad n=14 \quad\left(\mathrm{Cntn} 4^{+/-}\right), \quad n=14$ mice $\left(\mathrm{Cntn}_{4} 4^{-1}\right)$. Spine data $n=10 \quad\left(\mathrm{Cntn}^{+/+}\right), \quad n=14$ $\left(\mathrm{Cntn} 4^{+/-}\right)$, and $n=8$ mice $\left(\mathrm{Cntn} 4^{-/-}\right)$. Quantitative analysis was performed between genotypes, in each DG area, on at least six slices in $\mathrm{Cntn} 4^{+/+}, \mathrm{Cntn} 4^{+/-}$, and Cntn $4^{-/-}$ mice ( $n=5$ mice per genotype) using the unpaired Student's $t$ test and one-way ANOVA. Neuron data $n=22$ $\left(\mathrm{Cntn}^{+/+}\right), n=19\left(\mathrm{Cntn}^{+/-}\right)$, and $n=20$ mice $\left(\mathrm{Cntn} 4^{-/-}\right)$.

Plasma corticosterone levels were analyzed using the unpaired Student's $t$ test and one-way ANOVA $(n=31$ mice total, $n=8\left(\operatorname{Cntn}_{4}^{+/+}\right), n=12\left(\operatorname{Cntn}_{4}^{+/-}\right)$, and $n=$ 11 mice $\left.\left(\mathrm{Cntn}^{-/-}\right)\right)$.

Behavior: Mice were randomly assigned to behavioral tests. Buried food-seeking ( $n=38$ mice, $n=12\left(\mathrm{Cntn}^{+/+}\right)$, $n=13\left(\right.$ Cntn $\left.4^{+/-}\right), n=13$ mice $\left.\left(\operatorname{Cntn} 4^{-/-}\right)\right)$; object location $\left(n=37\right.$ mice, $n=11\left(\right.$ Cntn $\left.^{+/+}\right), n=13\left(\right.$ Cntn $\left.^{+/-}\right), n=13$ mice $\left.\left(C n t n 4^{-/-}\right)\right)$; object discrimination $(n=36$ mice, $n=11$ $\left(\mathrm{Cntn}^{+/+}\right), n=13\left(\mathrm{Cntn}^{+/-}\right), n=12$ mice $\left.\left(\mathrm{Cntn} 4^{-/-}\right)\right)$, and fear conditioning $\left(n=35\right.$ mice, $n=11\left(\mathrm{Cntn}^{+/+}\right), n=12$ $\left(\mathrm{Cntn} 4^{+-}\right), n=12$ mice $\left.\left(\mathrm{Cntn} 4^{-/-}\right)\right)$. Statistical analysis was performed between genotypes using the unpaired Student's $t$ test and one-way ANOVA.

Gross anatomy: metabolism $(n=38$ mice, $n=12$ $\left(\right.$ Cntn $\left.4^{+/+}\right), n=13\left(\right.$ Cntn $\left.^{+/-}\right), n=13$ mice $\left(\right.$ Cntn $\left.\left.4^{-/-}\right)\right)$; brain size $\left(n=21\right.$ mice, $n=6 \quad\left(C n t n 4^{+/+}\right), \quad n=9$ $\left(\mathrm{Cntn}^{+/-}\right), n=6$ mice $\left.\left(\mathrm{Cntn} 4^{-/-}\right)\right)$; brain weight $(n=22$ mice, $n=6\left(\right.$ Cntn $\left.^{+/+}\right), n=9\left(\right.$ Cntn $\left.^{+/-}\right), n=7$ mice $\left.\left(\mathrm{Cn} t n 4^{-/-}\right)\right)$. Statistical analysis was performed between genotypes using the unpaired Student's $t$ test and oneway ANOVA. 


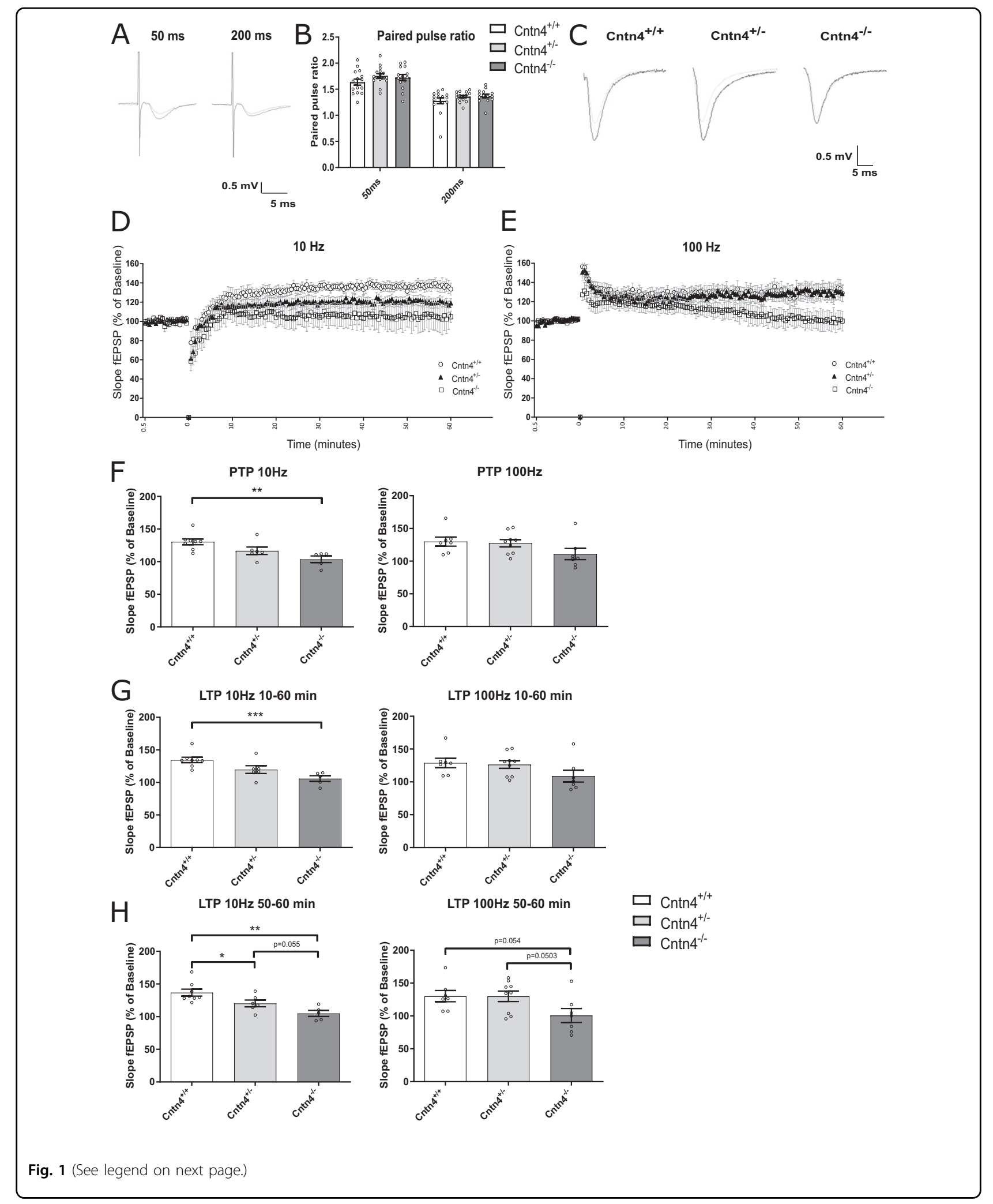


(see figure on previous page)

Fig. 1 The effect of Cntn4 deficiency on hippocampal synaptic potentiation. A Representative fEPSP traces of the paired pulse ratio (PPR) recorded in the CA1 area of each mouse genotype at $50 \mathrm{~ms}$ (left) and $200 \mathrm{~ms}$ interval (right). To allow comparison between traces, the response to the first (gray) and second pulse (black) are here superimposed. B Paired pulse ratio (expressed as [slope second pulse/slope first pulse] $\left.{ }^{*} 100 \%\right)$ in the hippocampal region at $50 \mathrm{~ms}$ and $200 \mathrm{~ms}$ inter-stimulus interval. Data between genotypes was analyzed by two-way ANOVA $(p=0.07)$.

C Representative individual fEPSP traces taken from each genotype. The gray traces represent the baseline fEPSP, the black trace was taken between 50 and 60 min after tetanic stimulation. D Stimulation with 900 pulses at $10 \mathrm{~Hz}$ induced synaptic potentiation in the CA1 region of hippocampal slices in all groups. E Stimulation with 900 pulses at $100 \mathrm{~Hz}$ induced synaptic potentiation in the CA1 region of hippocampal slices in all groups. $\mathbf{F}$ Average post-tetanic potentiation (PTP) measurements at $10 \mathrm{~Hz}$ and $100 \mathrm{~Hz}$, respectively. $p=0.003$. G Average synaptic potentiation over $60 \mathrm{~min}$ (i.e., from 10 to $60 \mathrm{~min}$ post-tetanus) at $10 \mathrm{~Hz}$ and $100 \mathrm{~Hz}$. $P=0.0009$. $\mathbf{H}$ Average synaptic potentiation between $50-60 \mathrm{~min}$ (i.e., from period between 50 to $60 \mathrm{~min}$

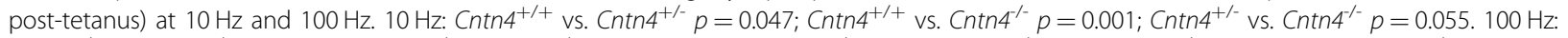

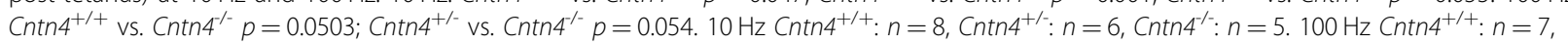

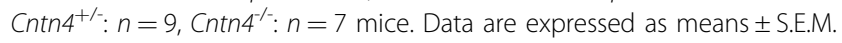

\section{Results}

\section{Gross anatomy and brain region specific expression}

In order to inspect brain development, we first evaluated the gross anatomy in $\mathrm{Cntn4^{-/- }}$ adult mice. We assessed body weight, total brain weight and total brain size to screen for gross anatomical differences and observed no significant difference between $\mathrm{Cntn}^{-/-}$, $C n t n 4^{+/-}$, and $C n t n 4^{+/+}$mice $(p>0.05$, one-way ANOVA, respectively) (Fig. $\mathrm{S} 1 \mathrm{~A}-\mathrm{C}$ ). The expression of Cntn4 is low in the DG based on the single-cell sequencing data of Habib et al. ${ }^{41}$. This was also demonstrated by measuring mRNA expression of Cntn4 in dissected cortical and hippocampal regions (CA1 and DG) by real-time PCR (RT-PCR) (Fig. S1, D). Expression analysis in wild-type mice revealed that $C n t n 4$ expression was significantly higher in the CA1 region of the hippocampus, compared to the cortex region. Conversely, Cntn4 expression is significantly lower in the DG region. Cntn4 protein in cortex and hippocampus extracted from adult male mice was measured by Western blotting, revealing a lack of Cntn4 protein expression in the cortex and hippocampus of the Cntn $4^{-/-}$mice (Fig. S1, E).

\section{Hippocampal CA1 synaptic potentiation was significantly reduced in $\mathrm{Cntn}^{+/-}$and $\mathrm{Cntn}^{-/-}$mice}

To test the role of Cntn4 in CA1 synaptic transmission and LTP, field excitatory postsynaptic potential recordings were performed in the CA1 region of the hippocampus from $\mathrm{Cntn} 4^{+/+}, \mathrm{Cntn} 4^{+/-}$, and $\mathrm{Cntn} 4^{-/-}$mouse brain slices using a previously described protocol ${ }^{36}$.

Baseline synaptic characteristics, i.e., half maximum slope of the fEPSP and baseline half maximal stimulus intensity were measured and revealed no significant genotype effects $(p>0.05$, two-way ANOVA) (Table S2).

To examine whether Cntn4 deficiency affected paired pulse facilitation, double pulse responses were recorded at $50 \mathrm{~ms}$ or $200 \mathrm{~ms}$ intervals. There was no observed genotype effect on paired pulse facilitation, at either interval ( $p>0.05$, two-way ANOVA) (Fig. 1A, B).

In mouse hippocampal slices, stimulation in CA1 stratum radiatum with 900 pulses at $10 \mathrm{~Hz}$ or
$100 \mathrm{~Hz}$, respectively, yielded synaptic potentiation differences between genotypes, which lasted for at least one hour (Fig. 1D, E). A significant depression in average synaptic potentiation was observed between the $\mathrm{Cntn} 4^{-/-}$ and $C n t n 4^{+/+}$mice at $10 \mathrm{~Hz}$ but less effect observed at $100 \mathrm{~Hz}$ (Fig. 1F-H). For example, the average PTP and LTP fEPSP slope (\% of baseline) at $10 \mathrm{~Hz}$ was reduced from 130 in $\mathrm{Cntn}_{4}^{+/+}$to 100 in $\mathrm{Cntn}^{-/-}$mice $\left(\mathrm{Cntn} 4^{+/+}\right.$ vs. $C n t n 4^{-/-} p=0.003$ and $p=0.0009$, respectively, unpaired Student's $t$ test, mean baseline vs. mean $60 \mathrm{~min}$ post-tetanic period). Recordings were carried out over a 60 min period; and LTP results are compared between two time ranges: the overall $10-60 \mathrm{~min}$ period and the final ten minutes (50-60 min period). A stimulation frequency of $10 \mathrm{~Hz}$ is commonly used to yield synaptic potentiation, however $100 \mathrm{~Hz}$ was also used to allow comparison between early and late LTP. These results indicated that Cntn4 deficiency had a more pronounced effect on early synaptic potentiation.

\section{Cntn4 deficiency leads to an increased hippocampus the CA1-3 surface area}

Gross anatomy results interestingly showed CA1 and CA3 area size are significantly increased in the Cntn4deficient brain, but not in DG (Fig. 2E, F). To investigate whether the Cntn4 knockout phenotype is region specific, we performed immunohistochemistry with two specific markers (synaptoporin and calbindin). These markers were used to highlight the network of hippocampal mossy fibers and their terminals (Fig. 2A). Synaptoporin (also known as Synaptophysin 2) is a component of the synaptic vesicle membrane but is chosen in this context since it is found to be concentrated in the mossy fiber synapses of the hippocampus ${ }^{42}$. Staining shows that synaptoporin was expressed in the mossy fiber system in the hilus of the dentate gyrus (DG) and revealed the suprapyramidal bundle (SPB) and infrapyramidal bundle $(\mathrm{IPB})^{42}$. Simultaneously, staining for the calcium-binding protein calbindin shows DG granular and mossy fiber axons ${ }^{43}$. The mossy fibers cross the stratum pyramidale (SP) of the CA3 region, which emanate from the DG, 

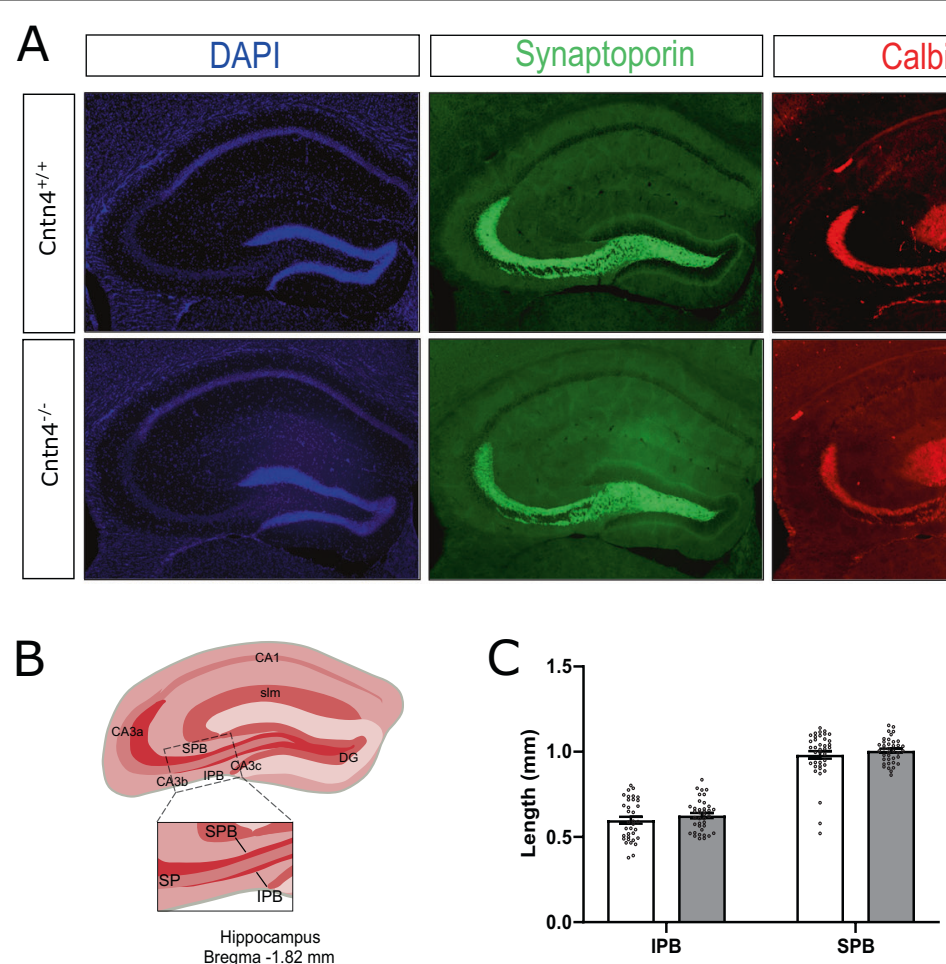

B

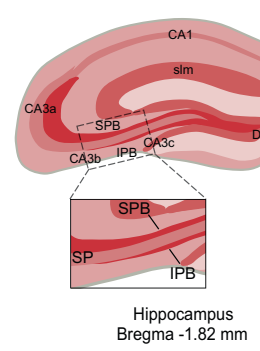

D

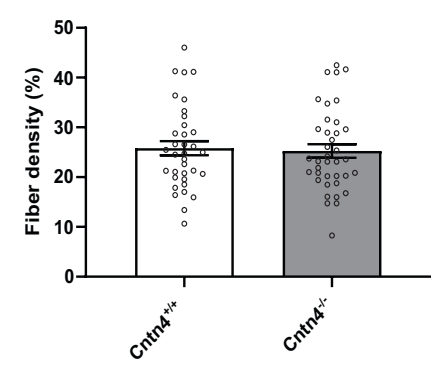

F

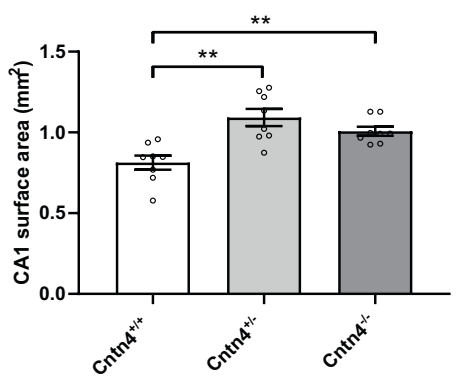

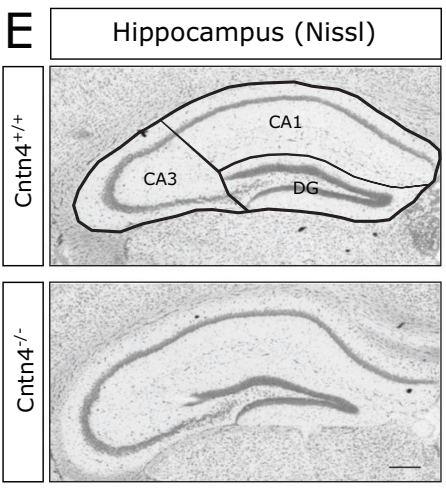

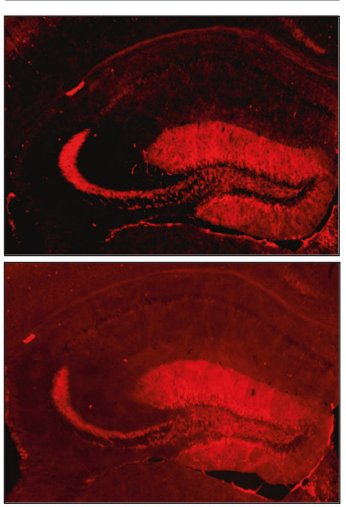

$\square \mathrm{Cntn}^{+/+} \square \mathrm{Cntn}^{- \text {- }^{-}}$

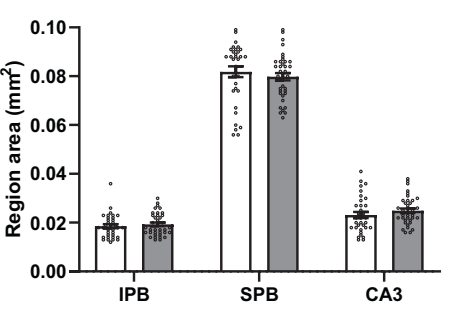

$\square \mathrm{Cntn}^{+/+} \square \mathrm{Cntn}^{+/-} \square \mathrm{Cntn}^{-/-}$
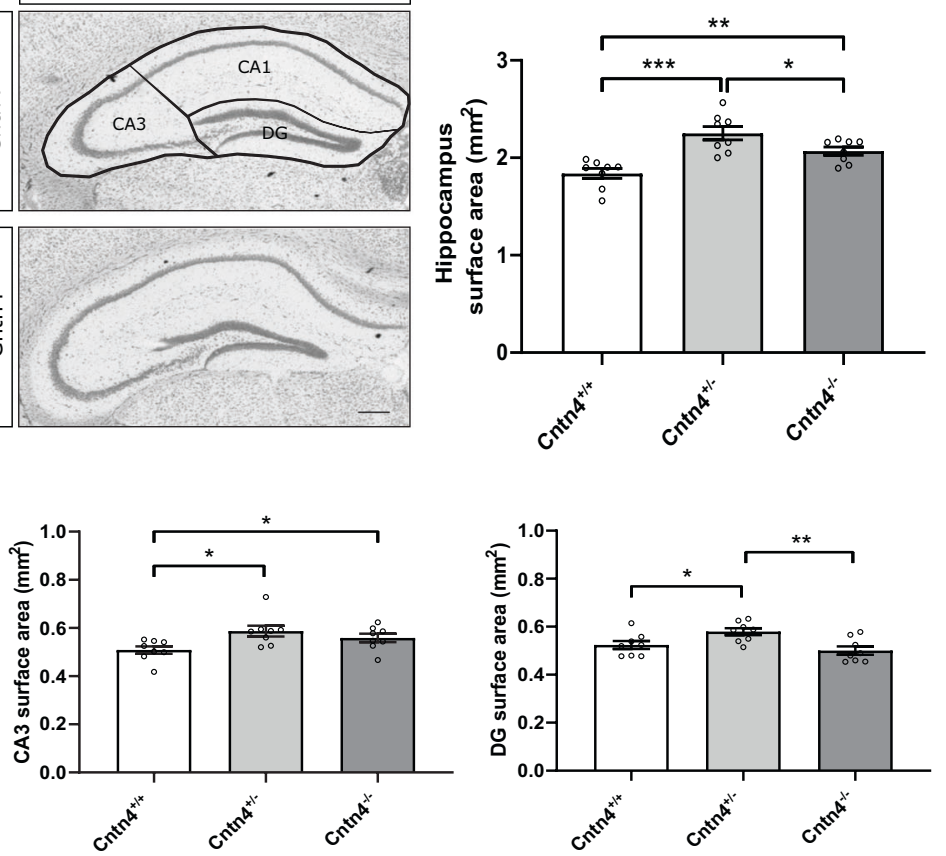

Fig. 2 (See legend on next page.) 
(see figure on previous page)

Fig. 2 Hippocampal mossy fiber distribution in Cntn4-deficient mice. A Representative image of synaptoporin (green) and calbindin (red) expression in adult $\mathrm{Cntn}^{+/+}$and $\mathrm{Cntn4^{-/ }}$ hippocampi. DAPI is in blue. The scale bars represent $250 \mu \mathrm{m}$. B Schematic representation of the adult mouse hippocampus. The rectangle indicates the area and location used for quantification of mossy fiber crossings in the SP of the CA3. Abbreviations: CA1 cornu ammonis, CA3a-c cornu ammonis 3a-c, DG dentate gyrus, SPB suprapyramidal bundle, IPB infrapyramidal bundle, SP stratum pyramidale, sIm stratum lacunosum-moleculare. C Quantification of the length (left panel) and area size (right panel) of the IPB, SPB, and CA3 in $\mathrm{Cntn}^{+/+}$and $\mathrm{Cntn}^{-/-}$mice showed no difference between genotypes. Analysis was performed on at least three sections per brain from $\mathrm{Cntn}^{+/+}$ and $C n t n 4^{-/-}$mice ( $n=6$ mice per genotype) using unpaired Student's $t$ test. Data are presented as mean \pm S.E.M. D Quantification of percentage of mossy fibers crossing the SP did not reveal a difference between $\mathrm{Cntn}^{+/+}$and $\mathrm{Cntn4^{-/ }}$ mice. Analysis was performed on at least three sections per brain from $\mathrm{Cntn}^{4^{+/+}}$and $\mathrm{Cntn} 4^{-/-}$mice ( $n=6$ mice per genotype) using unpaired Student's $t$ test. Data are presented as mean \pm S.E.M. E Nissl-stained sections of $\mathrm{Cntn}^{+/+}, \mathrm{Cntn4^{+/ }}$, and $\mathrm{Cntn} 4^{-/-}$mice demonstrated a significant difference in hippocampal surface areas between genotypes. $\mathbf{F}$ Tracing of hippocampal subsections revealed significant area differences across all regions. Analysis was performed on at least two sections per brain from $\mathrm{Cntn}^{+/+}, \mathrm{Cntn}^{+/-}$, and $\mathrm{Cntn} 4^{-/-}$mice ( $n=4$ mice per genotype) using unpaired Student's $t$ test and one-way ANOVA. Data are presented as mean \pm S.E.M, $p=0.0004,0.004,0.04$ (total hippocampus); $p=0.001,0.003$ (CA1); $p=0.01,0.048$ (CA3); $p=0.03,0.004$ (DG).

bifurcate and segregate into the SPB and IPB. Both mossy fiber bundles are located on either side of the SP, which is the layer containing pyramidal neuron somata (Fig. 2B). The density of mossy fiber bundles was measured. Quantification of the length and area size of the hippocampal IPB, SPB, and CA3 was carried out. The lengths and areas of the mossy fibers in IPB, SPB, and CA3 showed no differences between genotypes $(p>0.05$, one-way ANOVA) (Fig. 2C). The hippocampal mossy fiber distribution was quantified in Cntn4-deficient mice. The percentage of mossy fibers crossing the SP did not reveal a difference between $\mathrm{Cntn} 4^{+/+}$and $\mathrm{Cntn} 4^{-/-}$mice $(p>0.05$, one-way ANOVA) (Fig. 2D). Finally, Nisslstained sections of $\mathrm{Cntn} 4^{+/+}, \mathrm{Cntn} 4^{+/-}$, and Cntn $4^{-/-}$mice were analyzed. There is a significant difference in hippocampal surface areas between genotypes (Fig. 2E). $\mathrm{Cntn}^{-/-}$mice showed a bigger hippocampus (on average $2.07 \mathrm{~mm}^{2}$ ) compared to $\mathrm{Cntn} 4^{+/+}$(on average $1.84 \mathrm{~mm}^{2}$ ) $\left(\right.$ Cntn $^{+/+}$vs. Cntn $4^{-1-} p=0.004$, unpaired Student's $t$ test). This was attributed to significant increases in the CA1 and CA3 regions, respectively (Fig. 2F). Cntn $4^{-1-}$ mice showed bigger CA1 and CA3 (on average $1.01 \mathrm{~mm}^{2}$ and $0.56 \mathrm{~mm}^{2}$, respectively) compared to $\mathrm{Cntn} 4^{+/+}$(on average $0.81 \mathrm{~mm}^{2}$ and $0.51 \mathrm{~mm}^{2}$, respectively) $\left(\mathrm{Cntn} 4^{+/+}\right.$ vs. Cntn $4^{-/-} p=0.003$ and 0.048, unpaired Student's $t$ test). No significant difference was observed in cell or neuron number in the hippocampus $(p>0.05$, one-way ANOVA), aside from an increase in cell number in the DG (Figure S2A-B). These data show a selective enlargement of the hippocampus in animals with Cntn4 deficiency.

\section{Increased volume and surface area are found in the CA1 apical dendrites of $\mathrm{Cntn} 4$ deficient mice}

Our electrophysiological and morphological analysis revealed that Cntn4 may be involved in synaptic plasticity, and changes may affect neurons in the hippocampal CA1 region. Subsequently we investigated the morphology of neurons in the CA1 region in detail since Cntn4 is a key molecule in neural cell connection development. The morphology of pyramidal neurons and granule cells were analyzed in the CA1 and DG regions by quantitative Golgi analyses (Figs. 3 and 4). The apical and basal dendrite morphology of pyramidal neurons in CA1 was quantified from images of Golgi-stained mouse brains (Fig. 3A, B). The apical dendrites of $\mathrm{Cntn} 4^{-1-}$ mice have a significantly larger apical volume and surface area compared to $\mathrm{Cntn}_{4}^{+/-}$and Cntn $4^{+/+}$mice $\left(\mathrm{Cntn} 4^{-/-}\right.$vs. Cntn $4^{+/-} p=$ 0.04 and $\mathrm{Cntn}_{4}^{-1-}$ vs. Cntn $4^{+/+} p=0.02$, unpaired Student's $t$ test) (Fig. 3C). Sholl plots also indicated that the distribution of dendritic intersections and length differed between genotypes. $\mathrm{Cntn} 4^{-1-}$ mice have significantly more Sholl apical dendrite intersections $(3.0 \pm 0.33)$ in the range of $180-190 \mu \mathrm{m}$ from the soma, compared to Cntn $4^{+/}$ $(1.82 \pm 0.24)$ and $C n t n 4^{+/+}(1.94 \pm 0.26)$ mice $\left(C n t n 4^{-/-}\right.$vs. $\mathrm{Cntn}^{+/-} p=0.004$ and Cntn $4^{-/-}$vs. Cntn $4^{+/+} p=0.02$, unpaired Student's $t$ test) (Fig. 3D). CA1 basal dendrites were observed to have significantly reduced total neurite length in Cntn $4^{-/-}$mice $(878 \pm 94 \mu \mathrm{m})$ compared to the Cntn $^{+/-}(1231 \pm 133 \mu \mathrm{m})$ and Cntn $4^{+/+}(1153 \pm 84 \mu \mathrm{m})$ mice $\left(C_{n t n} 4^{-1-}\right.$ vs. Cntn $4^{+/-} p=0.04$ and $C n t n 4^{-/-}$vs. Cntn $4^{+/+} p=0.04$, unpaired Student's $t$ test) (Fig. 3E). The dendrites also have significantly smaller volume and surface area in $\mathrm{Cntn} 4^{-/-}$mice compared to the Cntn $4^{+/-}$ mice (Fig. 3E). Cntn $4^{+/-}$mice have significantly more Sholl basal dendrite intersections in the range of $30-50 \mu \mathrm{m}$ from the soma (12.6-14.9 intersections, respectively) compared to $\mathrm{Cntn} 4^{+/+}$mice (10-11 intersections, respectively) $\left(\mathrm{Cntn} 4^{+/-}\right.$vs. $\mathrm{Cntn} 4^{+/+} p=0.02$, $0.05,0.04$, respectively, unpaired Student's $t$ test). Cntn $4^{+/-}$mice have significantly longer Sholl basal dendrite lengths in the range $30-40 \mu \mathrm{m}\left(\mathrm{Cntn}_{4} 4^{+/-}\right.$vs. Cntn $4^{+/}$ ${ }^{+} p=0.03$, unpaired Student's $t$ test) (Fig. 3F).

Next, spine number and morphology of pyramidal neurons in the CA1 region of the hippocampus were analyzed (Fig. 3G), since spines play a key role in functional neuronal circuits. There was a significant decrease in total number of spines in Cntn $4^{+l-}(24.7 \pm 1.9)$ and Cntn $4^{-/-}(25.0 \pm 1.7)$ hippocampi compared to Cntn $4^{+/+}$ mice $(32.1 \pm 2.5)\left(\mathrm{Cntn} 4^{+/-}\right.$vs. Cntn $4^{+/+}$and $C n t n 4^{-/-}$vs. 


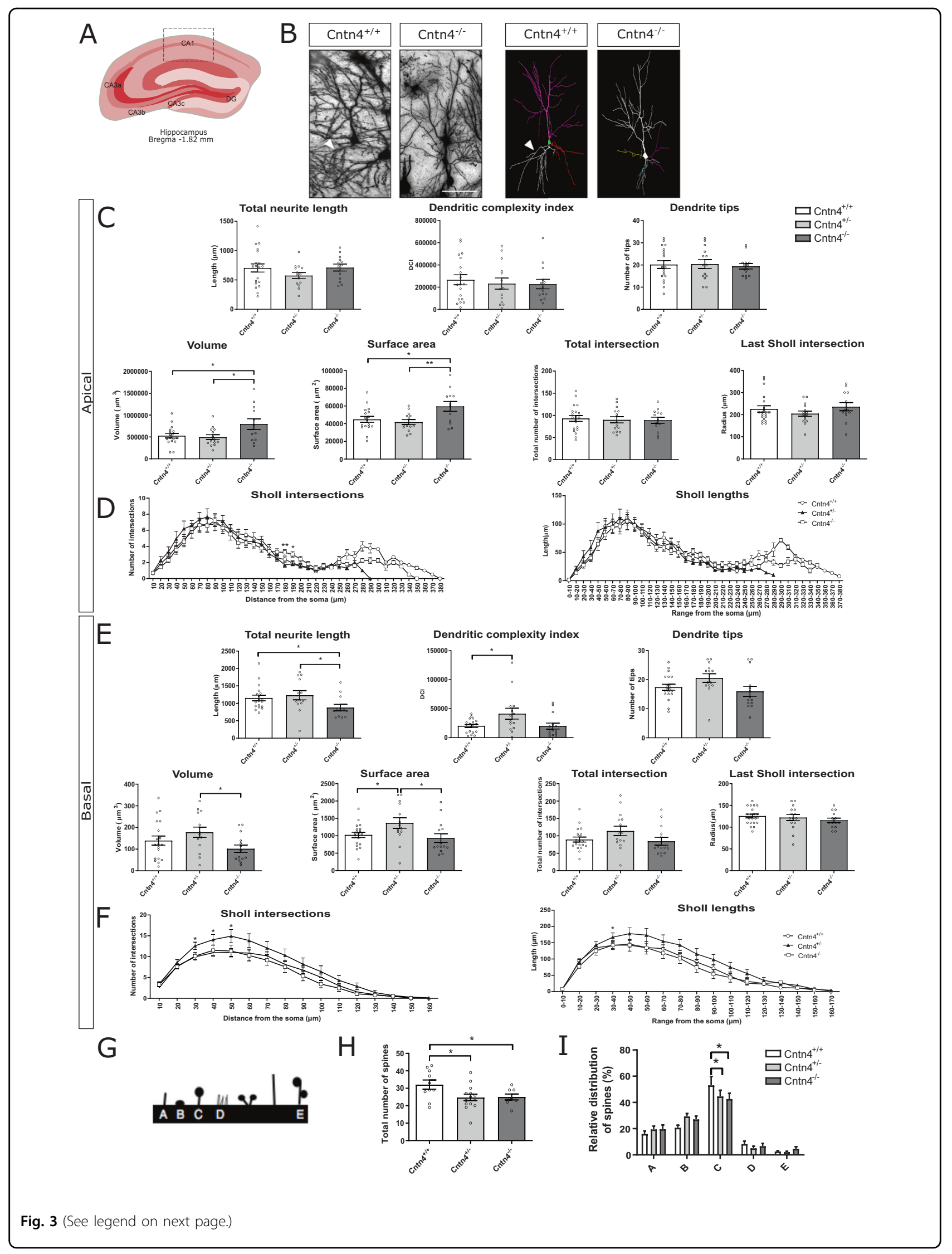


(see figure on previous page)

Fig. 3 Golgi analysis CA1. Neuron morphology analysis results for $\mathrm{Cntn} 4^{+/+}, \mathrm{Cntn} 4^{+/}$, and $\mathrm{Cntn} 4^{-/-}$mouse hippocampus CA1. A Schematic representation of the hippocampus CA1 with labeled Bregma anterior-posterior. Adapted from Paxinos and Franklin, 2001. B Golgi staining in $\mathrm{Cntn}^{+/+}$and $\mathrm{Cntn}^{-/-}$mouse hippocampus CA1 (left), exemplary tracings of pyramidal neurons (right). The scale bar represents $40 \mu \mathrm{m}$. The arrowheads show differences in basal neurite length. C, E Quantitative morphological results for the apical and basal dendrites respectively. $p=0.04$, 0.03 (apical volume); $p=0.02,0.007$ (apical surface area); $p=0.04,0.04$ (basal total neurite length); $p=0.02$ (basal dendritic complexity index); $p=$ 0.02 (basal volume); $p=0.04,0.04$ (basal surface area). $\mathbf{D}, \mathbf{F}$ Sholl plots indicate the distribution of respective apical and basal dendritic intersections and length at increasing distance from the center of the cell body. $p=0.004,0.02$ (apical Sholl intersection); $p=0.02,0.05,0.04$ (basal Sholl

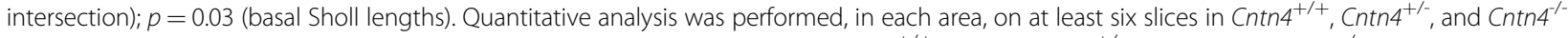
mice ( $n=5$ mice per genotype). Data are presented as mean \pm S. E. M, $n=19\left(C_{\left.n t n 4^{+/+}\right)}\right), n=14\left(C_{\left.n t n 4^{+/}\right)}\right), n=14$ mice $\left(C n t n 4^{-/}\right)$. G Schematic view of the five different spine morphology categories, $A=$ thin; $B=$ stubby; $C=$ mushroom; $D=$ abnormal (several types); $E=$ double mushroom. Quantitative morphological data on the first $25 \mu \mathrm{m}(50 \mu \mathrm{m}$ to $75 \mu \mathrm{m})$ of Golgi-stained branches of the proximal part of the apical dendrite in pyramidal neurons of the CA1 hippocampus region in $\mathrm{Cntn}_{4}^{+/+}, \mathrm{Cntn} 4^{+/}$, and $\mathrm{Cntn} 4^{-/-}$mice indicate a significant difference in $\mathbf{H}$ total number of spines (including all morphological categories), and I relative distribution of mushroom spines. Data are presented as mean $\pm \mathrm{S}$. E. M, $n=10$ (Cntn4 ${ }^{+/}$

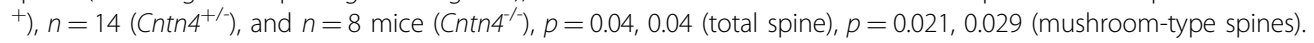

Cntn $4^{+/+} p=0.04$, respectively, unpaired Student's $t$ test) (Fig. 3H). Spine morphology analysis was performed to investigate possible changes in spine maturity in Cntn4 deficient mice. Analysis was focused in the apical dendrites since they project towards the DG, and fEPSP measurements were made here ${ }^{44,45}$. In the first $25 \mu \mathrm{m}$ $(50-75 \mu \mathrm{m})$ of the proximal part of the apical dendrite in pyramidal neurons of the CA1 hippocampus region, there was a significant reduction in the number of mushroom spines in Cntn4 $4^{+/-}(44.5 \% \pm 4.8 \%)$ and $\mathrm{Cntn}_{4}^{-/-}(42.5 \% \pm$ 4.4\%) hippocampi compared to Cntn $4^{+/+}(53.0 \% \pm 6.8 \%)$ mice $\left(\mathrm{Cntn}_{4}{ }^{+/-}\right.$vs. Cntn $4^{+/+} p=0.021$ and $\mathrm{Cntn} 4^{-/-}$vs. Cntn $4^{+/+} p=0.029$, unpaired Student's $t$ test) (Fig. 3I). In the second $25 \mu \mathrm{m}(75-100 \mu \mathrm{m})$ and in the total $50 \mu \mathrm{m}$, the total spine number of spines and the spine morphology were similar between genotype mice $(p>0.05$, one-way ANOVA).

Cntn4 is expressed less in the DG region compared to CA1. Therefore, to confirm the CA1 phenotype originates from Cntn4 deficiency, granule cell morphology in the DG was quantified from images of Golgi-stained mice brains (Fig. 4A, B). The granule cell quantitative morphological results, such as the total neurite length, showed no significant differences between genotypes ( $p>0.05$, one-way ANOVA) (Fig. 4C, D).

These data show both neurite and spine dysregulation in the CA1 region, and subsequently raise the possibility that hippocampus-mediated behaviors might have been affected by Cntn 4 deficiency.

\section{Cntn4-deficient mice demonstrate increased fear conditioning behavior}

In the next study, three types of learning and memory tasks were performed to test whether the altered hippocampal size and electrophysiological properties in Cntn 4 deficient mice are related to learning capacity. For that purpose, the following tasks were performed: food latency task, object discrimination task, object location task, and fear conditioning task. First, to evaluate the ability of mice to smell volatile odors, the buried food-seeking task was used. Latencies to find food revealed no significant genotype effect ( $p>0.05$, one-way ANOVA) (Fig. 5A). Second, spatial memory was tested using an object location task. In this task, all genotypes spent more time exploring the moved object. However, there was no significant difference in exploration time between them (Fig. 5B, D) $(p$ $>0.05$, one-way ANOVA, respectively). Similarly in the object discrimination task no genotype effects were observed ( $p>0.05$, one-way ANOVA). Thus, the altered hippocampal morphology and electrophysiolocal characteristics in Cntn4-deficient mice do not seem to be associated with spatial and declarative learning strategies.

Finally, a fear conditioning task was performed to test whether Cntn4 contributes to associative learning, as described previously ${ }^{40}$. Fear conditioning is based on the association of a neutral (conditioned) stimulus, such as a defined context (multisensory conditioning) or one cue (unisensory conditioning), with an aversive event, for example a foot shock (unconditioned stimulus). Responses, such as freezing, grooming, scanning, jumping, and rearing were monitored during the fear conditioning tests, as this behavior is indicative of anxiety and stress. The full results can be found in Fig. 5 and S3. We found significantly increased contextual fear conditioning in Cntn $4^{-/-}$mice (28\% freezing), compared to Cntn $4^{+/+}$mice (13\% freezing), quantified by a gene-dose dependent increase in freezing response $\left(\mathrm{Cntn} 4^{+/+}\right.$vs. Cntn $4^{-/-} p=$ 0.043, unpaired Student's $t$ test) (Fig. 5F). However, there was no difference observed between genotypes when exposed to a different context $(p>0.05$, one-way ANOVA, respectively) (Fig. 5G-K). Finally, in a different context plus a cue (Fig. S3G-K), Cntn $4^{-1-}$ mice froze significantly less (40\% freezing) than $\mathrm{Cntn}^{+/+}$mice $(60 \%$ freezing) (Cntn $4^{-1-}$ vs. Cntn $4^{+/+} p=0.01$, unpaired Student's $t$ test), but instead spent a significantly higher percentage of time grooming (Cntn $4^{-/-}$vs. Cntn $4^{+/+} p=$ 0.05 , unpaired Student's $t$ test). In addition to the behavioral responses, blood plasma corticosterone 


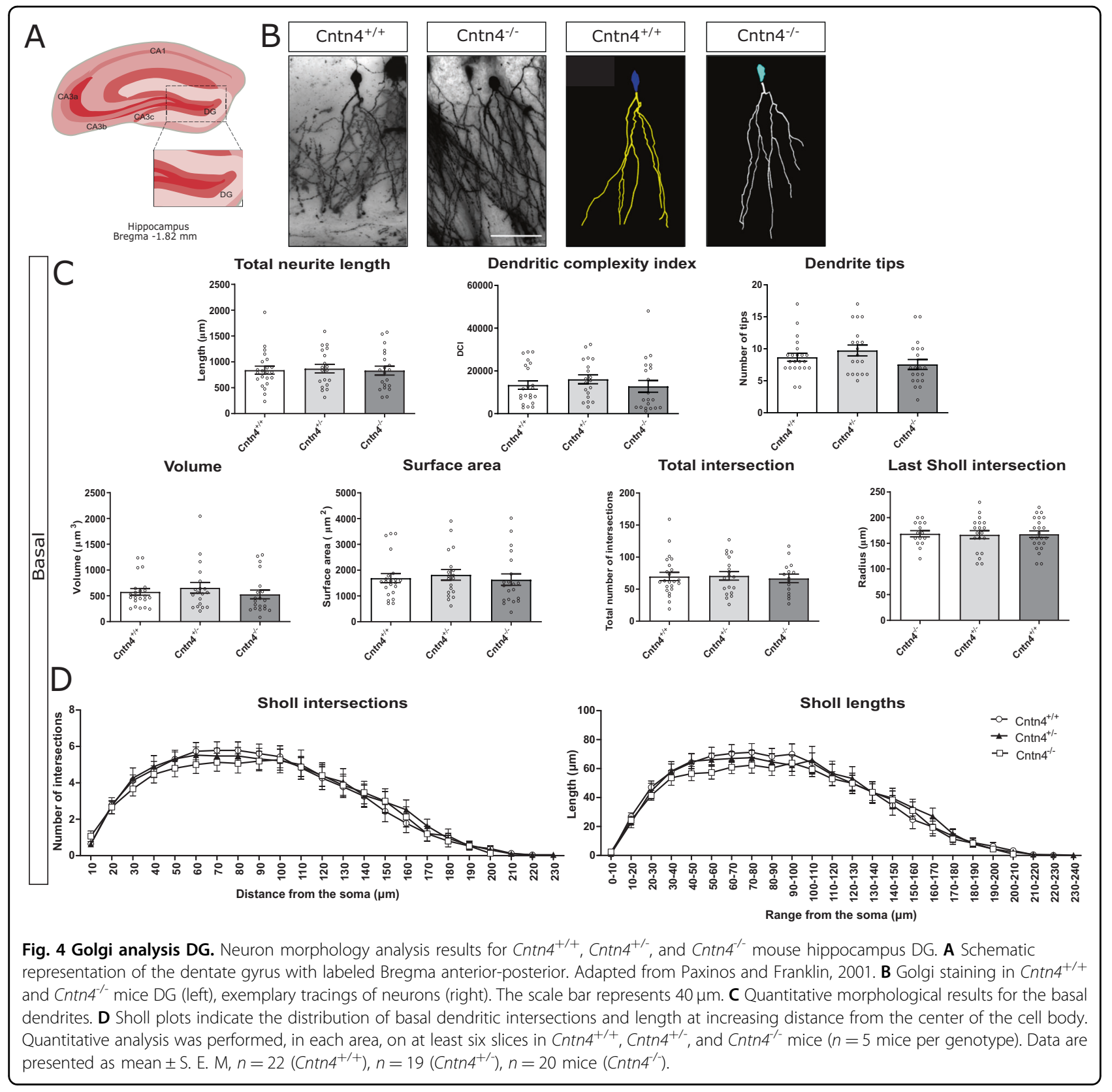

concentrations were assessed, in mice which had not undergone any protocols, to investigate whether the contextual fear conditioning responses may be related to changes in basal stress levels. Statistically significant higher levels of baseline blood corticosterone levels were observed in the Cntn $4^{+/-}(67 \mathrm{ng} / \mathrm{ml})$ and $\mathrm{Cntn}^{-/-}(55 \mathrm{ng} /$ $\mathrm{ml})$ mice compared to $\mathrm{Cntn} 4^{+/+}$mice $(34 \mathrm{ng} / \mathrm{ml})$ $\left(\right.$ Cntn $^{+/-}$vs. Cntn $4^{+/+} p=0.035$, and $C n t n 4^{-/-}$vs. Cntn $^{+/+} p=0.002$, unpaired Student's $t$ test) (Fig. 5L). These data indicate that Cntn4 deficiency results in selective changes in hippocampus-mediated behaviors, particularly expressed during fear conditioning.

\section{Discussion}

The Cntn4 protein has been characterized as a key cell adhesion molecule for axon guidance and neuronal connection in neuronal development, and previous studies suggest that CNTN4 is one of the risk genes that is associated with several neuropsychiatric disorders ${ }^{46}$. Here we show that Cntn4 deficiency contributes to hippocampal CA1 neural circuit morphology, synaptic plasticity, and associative learning. Thus, CNTN4 genetic mutations may affect hippocampal functionality at the neuro-anatomical, electrophysiological, and behavioral level which is of relevance to the display of maladaptive 


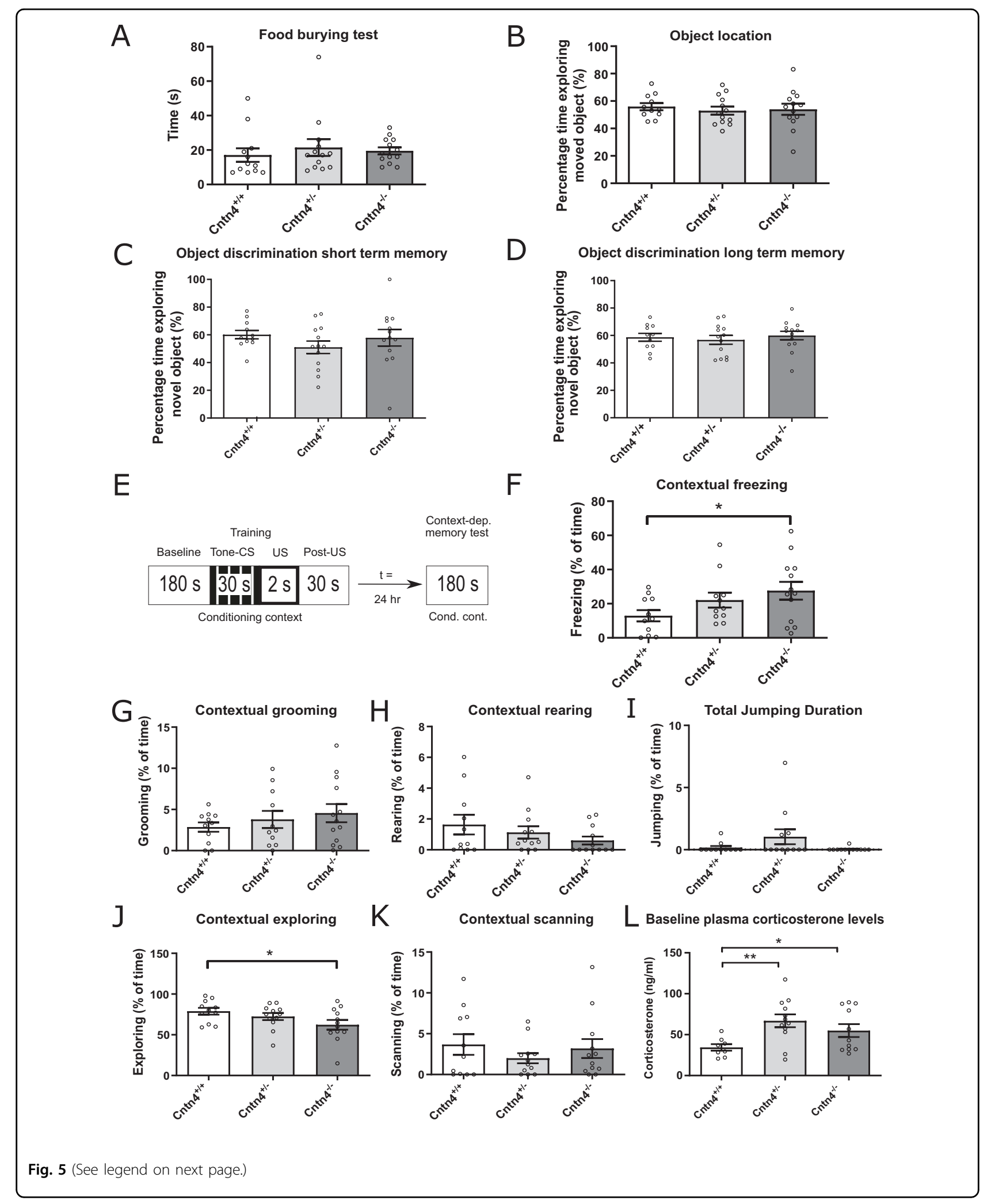


(see figure on previous page)

Fig. 5 Cntn4-deficient mice demonstrate same responses in object discrimination and object location tasks but altered fear conditioning responses. A Average time finding the piece of chow (sec) after $24 \mathrm{~h}$ of food restriction. The food finding time shows no significant difference between genotypes ( $n=38$ mice). B Average exploration time on moved object (\%). Calculated as Time novel $/ T_{i m e}$ novel+familiar. All genotypes spent more time exploring the moved object, however there was no significant difference in exploration time between them ( $n=37$ mice). C, D Shortterm and long-term recognition memory, respectively, in terms of average exploration time on novel object (\%). Calculated as Time novel $/$ Time $_{\text {novel }}$ + familiar. All genotypes spent more time exploring the moved object, however there was no significant difference in exploration time between them ( $n=36$ mice). Bars represent the means, error bars indicate the standard error of mean (S.E.M.). E Schematic presentation of the fear conditioning test sequence. $\mathbf{F}$ Percentage of time spent freezing during $180 \mathrm{~s}$ of exposure to a conditional context (without simulation such as tone or foot shock). $\mathrm{Cntn}^{-/-}$mice spent significantly more time freezing compared to $\mathrm{Cntn4^{+/+ }}$ mice ( $p=0.043, n=35$ mice). G-I Percentage of time spent grooming, rearing and jumping during $180 \mathrm{~s}$ of exposure to a conditional context (without simulation such as tone or foot shock) revealed no significant genotype effect. There was no significant genotype effect $(n=35$ mice). J Percentage of time spent exploring during $180 \mathrm{~s}$ of exposure to a conditional context (without simulation such as tone or foot shock). Cntn $4^{-/-}$mice spent significantly more time exploring compared to $\mathrm{Cntn} 4^{+/+}$ mice ( $p=0.034, n=35$ mice). $\mathbf{K}$ Percentage of time spent scanning during $180 \mathrm{~s}$ of exposure to a conditional context (without simulation such as tone or foot shock) ( $n=35$ mice). L Average baseline plasma corticosterone levels ( $\mathrm{ng} / \mathrm{ml}$ ) for each genotype. Both the $\mathrm{Cntn4^{+/- }}$ and $\mathrm{Cntn} 4^{-/-}$had significantly higher corticosterone levels than the $C n t n 4^{+/+}$mice $(p=0.035$ and $p=0.002$, respectively; $n=31$ mice). Bars represent the means, error bars indicate the standard error of mean (S.E.M.).

anxiety responses that are observed in several neuropsychiatric disorders ${ }^{47-49}$.

Our results show that synaptic potentiation was significantly decreased in Cntn $4^{-1-}$ mice (Fig. 1D, E). In addition, Golgi analyses revealed abnormal dendritic arborization of hippocampal CA1 pyramidal neurons (Fig. 3). This included increased volume and surface area of CA1 apical dendrites, with the opposite effect in basal dendrites (Fig. 3C). There are increased apical dendrite Sholl intersections at a distance from the cell soma (Fig. 3D). Interestingly, no abnormalities were observed in Golgi analyses of hippocampal DG granule cells (Fig. 4) which is in agreement with the absence of Cntn4 transcripts in the DG and supporting the argument that the phenotype in CA1 arises from Cntn4 deficiency ${ }^{21}$. We also examined if $\mathrm{Cntn} 4$ plays a role in the fasciculation of mossy fibers in the hippocampus in adult mouse brain (Fig. 2). This system is sensitive to axon guidance defects or to absence of certain CAMs, as was demonstrated in $\mathrm{Chl1}^{-1-}$ mice ${ }^{50,51}$. Mossy fibers represent the fasciculated axonal projections of DG granule cells on pyramidal cells in the hippocampus. Their terminals form synapses in the stratum lucidum with the proximal portion of the apical dendrites of CA3 pyramidal cells. Cntn4 deficiency does not affect the fiber density or morphology in the hippocampus. Since expression of Cntn 4 is very low to absent in the DG and highest in the CA1 and CA3 regions based on the single-cell sequencing data [41] and confirmed by our own qPCR data (Figure S1,D), the effect of Cntn4 deletion on neuronal morphologies would be much smaller in the DG than in the CA1 region. Thus, the DG vs. CA1 comparison on neuronal morphologies is important to show the impact of the Cntn4-deficiency, indicating that the morphological changes in the Cntn4 gene knockout neurons are specific to the lack of Cntn4 expression in this specific hippocampal region (Figs. 3 and 4). This suggests that Cntn4 regulates the neuronal functions specific in CA1, not in the DG, and supports the notion that Cntn4 is playing an important role in synaptic plasticity and memory formation in the hippocampus.

Morphological analysis of brains from Cntn4-deficient mice CA1 pyramidal neurons revealed that proximal segment spine number and mushroom-type spine number are decreased in Cntn4-deficient mice (Fig. 3). Mushroom-type spines have been described as memory spines $^{52,53}$, however they are also an indication of the upper limit synapse size and strength, and have little scope for synaptic strengthening ${ }^{54,55}$. This agrees with our observation that reduced mushroom-type spines are associated with impairments in synaptic potentiation and altered associative learning capacity (Figs. 1 and 5, respectively).

Reduced spine synapse density in the CA1 region of the hippocampus are observed in neuroserpin-deficient mice $^{56}$. Neuroserpin regulates the adhesion protein $\mathrm{N}$ cadherin, which similarly to the Contactin family has been linked to synapse formation ${ }^{57-59}$. Reduced spine density in CA1 hippocampus basal dendrites was also observed in two transgenic amyloid precursor protein (APP) mouse models of Alzheimer's disease, Tg2576 mice and APP/Lo mice $^{60}$. There are currently limited studies that show a genetic link between Cntn4 and Alzheimer disease ${ }^{11-13}$. Interestingly, APP has been reported as a Cntn4interacting protein $^{61}$ and this interaction regulates the promoting target-specific axon arborization in retinal ganglion cells ${ }^{24}$. Although further investigation is necessary, these spine alternations and synaptic potentiation dysfunction may be led by Cntn4/APP protein interaction. In addition, decreased spine density has been associated with altered hippocampal-dependent learning and memory in aged mice ${ }^{60,62}$, whereas strategies that promote spine formation correlate with memory improvement ${ }^{63}$. An association between spine density, hippocampal LTP and memory impairments has also been observed in other Alzheimer disease related animal models ${ }^{64,65}$. Therefore, our results relating a decrease in total number of spines to 
deficiency in synaptic potentiation and cognitive dysfunction are in line with previous findings.

Cntn 4 affects CA1 synaptic transmission and the ability to induce LTP in hippocampal slices. Stimulation in the CA1 stratum radiatum significantly decreased synaptic potentiation in Cntn4-deficient mice (Fig. 1D, E). This difference was observed across the induction and maintenance of LTP phases, indicating that there are deficits in both maintenance and induction in the absence of Cntn4. There was also a significant difference in the post-tetanic potentiation (PTP), which is strictly a presynaptic phenomenon $^{66}$. It is conspicuous that there are deficits in both LTP and PTP. However, no change in paired pulse ratio (PPR) indicates there is no disruption in the vesicle release of the presynaptic neurons and the type of receptors present at the postsynaptic neuron. These results therefore suggest that Cntn4 is involved in postsynaptic potentiation, in line with similar reports ${ }^{67,68}$. Reumann et al. observed that LTP differed significantly between neuroserpin-deficient mice and control littermates. The structure and density of dendritic spines correlates with synaptic function, measurable as $\operatorname{LTP}^{69}$. Whether the alteration in LTP is cause or consequence of the reduced spine-synaptic number observed in Cntn4deficient mice needs to be further investigated.

Our results show morphological and functional deficits in the hippocampus, leading to the question if this phenotype translates to behavioral deficits, especially related to learning and memory performance. For that purpose, short- and long-term recognition memory, spatial memory and fear conditioning responses were assessed. Buried food-seeking, object location, and discrimination (Fig. 5A-D) did not differ between Cntn $4^{-/-}$and control mice. In the fear conditioning task, genotype differences were observed, indicating that associative learning processes are affected as a function of Cntn4 deficiency (Fig. 5F-K). The context-dependent test phase of this learning paradigm demonstrates hippocampal impairment, however the cue-dependent test (Figure S3G-K) suggests impairment independent of the hippocampus, possibly the amygdala $^{70,71}$. The cue-dependent test did, however, reveal fear response behavior through significantly increased percentage of time spent grooming. These and earlier results from $\mathrm{Cntn} 4$ gene knockout mice ${ }^{72}$ consistently indicate that the morphological and electrophysiological changes in these mice do have functional consequences at the behavioral level. For example, in addition to the fear conditioning phenotype from the present study, Molenhuis et al. showed increased startle responsiveness and enhanced acquisition in a spatial learning task in Cntn4-deficient mice ${ }^{72}$. There is a notable discrepancy between the impaired CA1 LTP and reduction in CA1 spine number, and the longer contextual freezing time. For this translation it is important to realize that Cntn4 is also expressed by other brain regions, like the cortex, which may contribute to the ultimate behavioral response. For example, it is worth noting that the spatial overlap between Cntn4 and Cntn6 expression ${ }^{32,34}$, and evidence of motor impairments caused by Cntn6 deficiency in the cortex ${ }^{73}$, may result in Cntn 4 deficiency in the cortex to impact the behavior in the hippocampus. Interestingly, hippocampus morphological and electrophysiological deficits are well documented to be associated with memory and cognition deficits. The present study shows, however, that despite these hippocampal deficits, Cntn4 does not contribute to general cognitive impairment. Instead, some specific domains related to associative learning seem to be affected. However, considering the increased baseline corticosterone levels in the Cntn4-deficient mice, additional experiments are needed to investigate the relationship between Cntn4 deficiency, stress responsiveness, and hippocampal functioning.

Together, our neuro-anatomical, electrophysiological, and behavioral results in Cntn4-deficient mice suggest that Cntn4 has important functions related to synaptic plasticity and associative learning which occur in association with the neuronal morphological and synaptic plasticity changes in hippocampus CA1 neurons. The results indicate that Cntn4 plays an important role in pathways that regulate spine morphogenesis, and that dendritic spines could be important substrates of pathogenesis caused by the loss-of-function of Cntn4. Our approach will permit future evaluation of how variation in Cntn 4 may act to modulate risk and phenotypic presentation in neuropsychiatric patients with a loss or additional copy of this gene. Brain morphology and histopathology can be an important read-out to identify shared risk factors, and help to unravel the etiology of neuropsychiatric disorders. Further work is required to explain the molecular pathways of $\mathrm{Cntn} 4$ contribution to synaptic plasticity and its behavioral consequences.

\footnotetext{
Acknowledgements

We thank Dr. Yoshihiro Yoshihara, RIKEN BSI, for providing the Cntn4 mice and helpful advice. We thank Mr. Henk Spierenburg for performing the genotyping of the animals. This research was supported by the Canon Foundation in Europe research fellowship grants (to A.O-A). This publication has been supported by funding from the Innovative Medicines Initiative 2 Joint Undertaking (JU) under grant agreement No 777394 for the project AIMS-2TRIALS. This Joint Undertaking receives support from the European Union's Horizon 2020 research and innovation programme and EFPIA and AUTISM SPEAKS, Autistica, SFARI (to MJK). The views expressed are those of the authors and not necessarily those of the IMI $2 \mathrm{JU}$.
}

\section{Author details}

${ }^{1}$ University of Exeter Medical School, University of Exeter, Exeter EX2 5DW, UK ${ }^{2}$ Department of Translational Neuroscience, Brain Center Rudolf Magnus, UMC Utrecht, Stratenum 4.205, P.O. Box 85060, 3508 AB Utrecht, The Netherlands. ${ }^{3}$ Department of Molecular Neurobiology, Donders Institute for Brain, Cognition and Behaviour and Radboud University, Nijmegen, Netherlands. ${ }^{4}$ Faculty of Medical Sciences, University of Groningen, Groningen, The Netherlands. ${ }^{5}$ Groningen Institute for Evolutionary Life Sciences, University of Groningen, Groningen, The Netherlands 


\section{Conflict of interest}

The authors declare that they have no conflict of interest.

\section{Publisher's note}

Springer Nature remains neutral with regard to jurisdictional claims in published maps and institutional affiliations.

Supplementary information The online version contains supplementary material available at https://doi.org/10.1038/s41398-021-01223-y.

Received: 19 May 2020 Revised: 5 January 2021 Accepted: 18 January 2021 Published online: 04 February 2021

\section{References}

1. World Health Organization. Depression and other common mental disorders: global health estimates. Geneva: World Health Organization; (2017). Licence: CC BY-NC-SA 3.0 IGO.

2. Zhao, Y. \& Castellanos, F. X. Annual research review: discovery science strategies in studies of the pathophysiology of child and adolescent psychiatric disorders - promises and limitations. J. Child Psychol. Psychiatry 57, 421-439 (2016).

3. Kirov, G. CNVs in neuropsychiatric disorders. Hum. Mol. Genet. 24, R45-R49 (2015).

4. Geschwind, D. H. \& Levitt, P. Autism spectrum disorders: developmental disconnection syndromes. Curr. Opin. Neurobiol. 17, 103-111 (2007).

5. Rubenstein, J. L. R. Annual research review: development of the cerebral cortex: implications for neurodevelopmental disorders. J. Child Psychol. Psychiatry Allied Discip. 52, 339-355 (2011).

6. $\mathrm{Hu}, \mathrm{Q}$. D. et al. F3/contactin acts as a functional ligand for notch during oligodendrocyte maturation. Cell 115, 163-175 (2003).

7. Sakurai, K. et al. Contribution of the neural cell recognition molecule NB-3 to synapse formation between parallel fibers and Purkinje cells in mouse. Dev. Neurobiol. 69, 811-824 (2009).

8. Peles, E. \& Salzer, J. L. Molecular domains of myelinated axons. Curr. Opin. Neurobiol. 10, 558-565 (2000).

9. Ye, $\mathrm{H}$. et al. Neural recognition molecules $\mathrm{CHL} 1$ and NB-3 regulate apical dendrite orientation in the neocortex via PTPa. EMBO J. 27, 188-200 (2008).

10. Wang, $K$. et al. A genome-wide association study on common SNPs and rare CNVs in anorexia nervosa. Mol. Psychiatry 16, 949-959 (2011).

11. Blacker, D. et al. Results of a high-resolution genome screen of 437 Alzheimer's Disease families. Hum. Mol. Genet. 12, 23-32 (2003).

12. Chittoor, G. et al. GWAS and transcriptional analysis prioritize ITPR1 and CNTN4 for a serum uric acid 3p26 QTL in Mexican Americans. BMC Genom. 17, 1-8 (2016).

13. Bamford, R. A. et al. The interaction between contactin and amyloid precursor protein and its role in Alzheimer's disease. Neuroscience 424, 184-202 (2020).

14. Fromer, $M$. et al. Gene expression elucidates functional impact of polygenic risk for schizophrenia. Nat. Neurosci. 19, 1442-1453 (2016).

15. Zhao, Z. et al. Association study of 167 candidate genes for Schizophrenia selected by a multi-domain evidence-based prioritization algorithm and neurodevelopmental hypothesis. PLoS One 8, e67776 (2013).

16. Mercati, $\mathrm{O}$. et al. Contactin $4,-5$ and -6 differentially regulate neuritogenesis while they display identical PTPRG binding sites. Biol. Open 2, 324-334 (2013).

17. Yoshihara, Y. et al. Overlapping and differential expression of BIG-2, BIG-1, TAG1, and F3: four members of an axon-associated cell adhesion molecule subgroup of the immunoglobulin superfamily. J. Neurobiol. 28, 51-69 (1995).

18. Kamei, Y. et al. Human NB-2 of the contactin subgroup molecules: chromosomal localization of the gene (CNTN5) and distinct expression pattern from other subgroup members. Genomics 69, 113-119 (2000).

19. Harris, T. J. C. \& Siu, C.-H. Reciprocal raft-receptor interactions and the assembly of adhesion complexes. BioEssays 24, 996-1003 (2002).

20. Zuko, A. et al. Contactins in the neurobiology of autism. Eur. J. Pharmacol. 719, 63-74 (2013).

21. Hodge, R. D. et al. Conserved cell types with divergent features in human versus mouse cortex. Nature 573, 61-68 (2019).

22. Fernandez, T. et al. Disruption of contactin 4 (CNTN4) results in developmental delay and other features of $3 p$ deletion syndrome. Am. J. Hum. Genet. 74 1286-1293 (2004).
23. Kaneko-Goto, T., Yoshihara, S.-I., Miyazaki, H. \& Yoshihara, Y. BIG-2 mediates olfactory axon convergence to target glomeruli. Neuron 57, 834-846 (2008),

24. Osterhout, J. A., Stafford, B. K., Nguyen, P. L., Yoshihara, Y. \& Huberman, A. D. Contactin-4 mediates axon-target specificity and functional development of the accessory optic system. Neuron 86, 985-999 (2015).

25. Julich K., Sahin M. Comprehensive Guide to Autism (Springer New York, 2014).

26. Fioravanti, M., Carlone, O., Vitale, B., Cinti, M. E. \& Clare, L. A meta-analysis of cognitive deficits in adults with a diagnosis of schizophrenia. Neuropsychol. Rev. 15, 73-95 (2005)

27. Landsiedel, J., Williams, D. M. \& Abbot-Smith, K. A meta-analysis and critical review of prospective memory in autism spectrum disorder. J. Autism Dev. Disord. 47, 646-666 (2017).

28. Terhoeven, $\mathrm{V}$. et al. Meaningful memory in acute anorexia nervosa patientscomparing recall, learning, and recognition of semantically related and semantically unrelated word stimuli. Eur. Eat. Disord. Rev. 25, 89-97 (2017).

29. Cremer, H., Chazal, G., Goridis, C. \& Represa, A. NCAM is essential for axonal growth and fasciculation in the hippocampus. Mol. Cell Neurosci. 8, 323-335 (1997).

30. Heyden, A., Angenstein, F., Sallaz, M., Seidenbecher, C. \& Montag, D. Abnormal axonal guidance and brain anatomy in mouse mutants for the cell recognition molecules close homolog of $\mathrm{L} 1$ and NgCAM-related cell adhesion molecule. Neuroscience 155, 221-233 (2008).

31. Montag-Sallaz, M., Schachner, M. \& Montag, D. Misguided axonal projections, neural cell adhesion molecule 180 mRNA upregulation, and altered behavior in mice deficient for the close homolog of L1. Mol. Cell Biol. 22, 7967-7981 (2002).

32. Zuko, A. et al. Developmental role of the cell adhesion molecule Contactin- 6 in the cerebral cortex and hippocampus. Cell Adhes. Migr. 10 378-392 (2016).

33. Zuko, A. et al. Association of cell adhesion molecules Contactin-6 and Latrophilin-1 regulates neuronal apoptosis. Front. Mol. Neurosci. 9, 1-16 (2016).

34. Zuko, A., Bouyain, S., Van Der Zwaag, B. \& Burbach, J. P. H. Contactins: structural aspects in relation to developmental functions in brain disease. Adv. Protein Chem. Struct. Biol. 84, 143-180 (2011)

35. Sarabdjitsingh, R. A. et al. Ultradian corticosterone pulses balance glutamatergic transmission and synaptic plasticity. Proc. Natl Acad. Sci. 111, 14265-14270 (2014).

36. Sarabdjitsingh, R. A. et al. Inhibiting 11ß-hydroxysteroid dehydrogenase type 1 prevents stress effects on hippocampal synaptic plasticity and impairs contextual fear conditioning. Neuropharmacology 81, 231-236 (2014).

37. Wiegert, O., Joels, M. \& Krugers, H. Timing is essential for rapid effects of corticosterone on synaptic potentiation in the mouse hippocampus. Learn. Mem. 13, 110-113 (2006).

38. Sarabdjitsingh, R. A., Meijer, O. C. \& de Kloet, E. R. Specificity of glucocorticoid receptor primary antibodies for analysis of receptor localization patterns in cultured cells and rat hippocampus. Brain Res. 1331, 1-11 (2010).

39. Molenhuis, R. T., de Visser, L., Bruining, H. \& Kas, M. J. Enhancing the value of psychiatric mouse models; differential expression of developmental behavioral and cognitive profiles in four inbred strains of mice. Eur. Neuropsychopharmacol. 24, 945-954 (2014).

40. Bruining, $H$. et al. Genetic mapping in mice reveals the involvement of Pcdh9 in long-term social and object recognition and sensorimotor development. Biol. Psychiatry 78, 485-495 (2015).

41. Habib, N. et al. Div-Seq: single-nucleus RNA-Seq reveals dynamics of rare adult newborn neurons. Science 353, 925-928 (2016).

42. Singec, I. et al. Synaptic vesicle protein synaptoporin is differently expressed by subpopulations of mouse hippocampal neurons. J. Comp. Neurol. 452, 139-153 (2002).

43. Scharfman, H. E., Goodman, J. H. \& Sollas, A. L. Granule-like neurons at the hilar/ CA3 border after status epilepticus and their synchrony with area CA3 pyramidal cells: functional implications of seizure-induced neurogenesis. J. Neurosci. 20, 6144-6158 (2000).

44. Tjia, M., Yu, X., Jammu, L. S., Lu, J. \& Zuo, Y. Pyramidal neurons in different cortical layers exhibit distinct dynamics and plasticity of apical dendritic spines. Front. Neural Circuits 11, 1-10 (2017).

45. Jiang, M. et al. Dendritic arborization and spine dynamics are abnormal in the mouse model of MECP2 duplication syndrome. J. Neurosci. 33, 19518-19533 (2013).

46. Oguro-Ando, A., Zuko, A., Kleijer, K. T. E. \& Burbach, J. P. H. A current view on contactin-4, -5 , and -6 : implications in neurodevelopmental disorders. Mol. Cell Neurosci. 81, 72-83 (2017). 
47. Lai, M.-C., Lombardo, M. V., \& Baron-Cohen, S. Autism. Lancet 383, 896-910 (2014).

48. Guarda, A. S., Schreyer, C. C., Boersma, G. J., Tamashiro, K. L. \& Moran, T. H. Anorexia nervosa as a motivated behavior: relevance of anxiety, stress, fear and learning. Physiol. Behav. 152, 466-472 (2015).

49. Braga, R. J., Reynolds, G. P. \& Siris, S. G. Anxiety comorbidity in schizophrenia. Psychiatry Res. 210, 1-7 (2013).

50. Hitt, B. et al. $\beta$-Site amyloid precursor protein (APP)-cleaving enzyme 1 (BACE1)-deficient mice exhibit a close homolog of L1 (CHL1) loss-of-function phenotype involving axon guidance defects. J. Biol. Chem. 287, 38408-38425 (2012).

51. Martin E. A. et al. The intellectual disability gene Kirrel3 regulates target-specific mossy fiber synapse development in the hippocampus. Elife 4, elife.09395 (2015).

52. Bourne, J. \& Harris, K. M. Do thin spines learn to be mushroom spines that remember? Curr. Opin. Neurobiol. 17, 381-386 (2007).

53. Mahmmoud, R. R. et al. Spatial and working memory is linked to spine density and mushroom spines. PLoS One 10, e0139739 (2015).

54. Harris, K., Jensen, F. \& Tsao, B.Three-dimensionalstructure of dendritic spines and synapses in rat hippocampus (CA1) at postnatal day 15 and adult ages: implications for the maturation of synaptic physiologyand long-term potentiation J. Neurosci. 12, 2685-2705 (1992). publishederratum appears in J Neurosci 1992 Aug;1.

55. Berry, K. P. \& Nedivi, E. Spine dynamics: are they all the same? Neuron $\mathbf{9 6}$ 43-55 (2017).

56. Reumann, $\mathrm{R}$. et al. The serine protease inhibitor neuroserpin is required for normal synaptic plasticity and regulates learning and social behavior. Learn Mem. 24, 650-659 (2017).

57. Lee, T. W., Coates, L. C. \& Birch, N. P. Neuroserpin regulates N-cadherinmediated cell adhesion independently of its activity as an inhibitor of tissue plasminogen activator. J. Neurosci. Res. 86, 1243-1253 (2008).

58. Leshchyns'ka, I. \& Sytnyk, V. Synaptic cell adhesion molecules in Alzheimer's disease. Neural Plast. 2016, 1-9 (2016).

59. Shimoda, Y., Koseki, F., Itoh, M., Toyoshima, M. \& Watanabe, K. A ciscomplex of NB-2/contactin-5 with amyloid precursor-like protein 1 is localized on the presynaptic membrane. Neurosci. Lett. 510, 148-153 (2012).
60. Perez-Cruz, C. et al. Reduced spine density in specific regions of CA1 pyramidal neurons in two transgenic mouse models of Alzheimer's disease. J. Neurosci. 31, 3926-3934 (2011).

61. Osterfield, M., Egelund, R., Young, L. \& Flanagan, J. Interaction of amyloid precursor protein with contactins and NgCAM in the retinotectal system. Development 135, 1189-1199 (2008).

62. von Bohlen und Halbach, O., Zacher, C., Gass, P. \& Unsicker, K. Age-related alterations in hippocampal spines and deficiencies in spatial memory in mice. J. Neurosci. Res. 83, 525-531 (2006).

63. Snigdha, S. et al. H3K9me3 inhibition improves memory, promotes spine formation, and increases BDNF levels in the aged hippocampus. J. Neurosci. 36, 3611-3622 (2016).

64. Weeber, E. J. et al. Reelin and ApoE receptors cooperate to enhance hippocampal synaptic plasticity and learning. J. Biol. Chem. 277, 39944-39952 (2002).

65. Rogers, J. T. et al. Reelin supplementation enhances cognitive ability, synaptic plasticity, and dendritic spine density. Learn. Mem. 18, 558-564 (2011).

66. Zucker, R. S. \& Regehr, W. G. Short-term synaptic plasticity. Annu. Rev. Physiol. 64, 355-405 (2002)

67. Weng, S.-M., McLeod, F., Bailey, M. E. S. \& Cobb, S. R. Synaptic plasticity deficits in an experimental model of rett syndrome: long-term potentiation saturation and its pharmacological reversal. Neuroscience 180, 314-321 (2011).

68. Nicoll, R. A. Expression mechanisms underlying long-term potentiation: a postsynaptic view. Philos. Trans. R. Soc. Lond. Ser. B Biol. Sci. 358, 721-726 (2003).

69. Holtmaat, A. \& Svoboda, K. Experience-dependent structural synaptic plasticity in the mammalian brain. Nat. Rev. Neurosci. 10, 647-658 (2009).

70. Goosens, K. A. Contextual and auditory fear conditioning are mediated by the lateral, basal, and central amygdaloid nuclei in rats. Learn. Mem. 8, 148-155 (2001).

71. Vazdarjanova, A. \& McGaugh, J. L. Basolateral amygdala is not critical for cognitive memory of contextual fear conditioning. Proc. Natl Acad. Sci. 95 15003-15007 (1998).

72. Molenhuis, R. T. et al. Limited impact of Cntn4 mutation on autism-related traits in developing and adult C57BL/6J mice. J. Neurodev. Disord. 8, 6 (2016).

73. Takeda, Y. et al. Impaired motor coordination in mice lacking neural recognition molecule NB-3 of the contactin/F3 subgroup. J. Neurobiol. 56, 252-265 (2003). 